\title{
No Evidence Indicates Famotidine Reduces the Risk of Serious Disease in COVID-19 Patients After Propensity Score Matching: Meta-Analysis and Systematic Reviews
}

\author{
Weizheng $\mathrm{Li}^{1}{ }^{1} \cdot$ Yongxue Dong $^{1} \cdot$ Xianmei Lei $^{1}$
}

Received: 4 June 2021 / Accepted: 3 August 2021 / Published online: 1 September 2021

(c) The Author(s) 2021, corrected publication 2021

We read the article by Sun et al. published in Digestive Diseases and Sciences with great interest.

It finds famotidine has no statistically significant difference in reducing the risk of serious disease in COVID19 patients [1]. Meanwhile, it was found that famotidine increased the risk of severe disease in COVID-19 patients after the Propensity Score Matching in Zhou's article [2]. Because of these contradictory conclusions, we would like to further explore the effect of Propensity Score Matching on famotidine through meta-analysis.

A total of 158 articles were searched from Pubmed, Embase, and Web of Science databases up to 21/05/2021. The following terms were used: ((SARS-CoV-2) or (COVID19) or (COVID-19) or (2019-nCoV) or (Coronavirus Disease-19)) AND ((Ranitidine) OR (Ometidine) OR (Famotidine) OR (Cimetidine)). The following criteria were used to include studies: 1. Famotidine use versus famotidine non-use. 2. COVID-19. 3. Human study. 4. Propensity Score Matching study. The following criteria were used to exclude studies: 1. Meta-analysis. 2. duplicate. The last 4 articles were included [2-5]. The HR values of Propensity Score Matching from 4 articles were extracted, the patient's serve disease or death or intubation data of famotidine and non-famotidine were converted into the corresponding log (RR) and SE (considering the low mortality of COVID19, it can be considered that the HR value is equivalent to the OR value) (Table 1). Finally, statistical analysis was performed by Revman 5.3, including forest plot, funnel plot, heterogeneity test, etc. (Figs. 1, 2). Considering the large heterogeneity observed in the results (I2 $=91 \%$, heterogeneity $=0.28$ ), the random-effects model was performed. The pooled RR value was $0.82, \mathrm{CI}(0.46,1.45) P=0.49$ indicated that after
Propensity Score Matching, the correlation between the use and non-use of famotidine in COVID-19 patients with the serious illness was not statistically significant, and the $P$-value is over 0.05 (Figs. 1, 2).

Finally, the article by Freedberg et al. was an observational study that cannot exclude the possibility of unmeasurable confounding factors or hidden biases and performed insignificant differences between use and non-use of famotidine reducing the risk of serious disease in COVID-19 patients [3]. This was a single-center study, which may limit the generality of the findings [3]. Zhou et al. indicated that the use of famotidine may increase the risk of severe COVID-19 disease after Propensity Score Matching [2]. However, Mather et al. believed that the matching of propensity scores to adjust for age differences between famotidine and non-famotidine patients did not change the significance of the differences in mortality or combined mortality and intubation in the analysis [4]. Similarly, Shoaibi et al. stated that with real-world data from a large multi-agency hospital database, no evidence has been found that famotidine used in hospitalized COVID-19 patients reduced the risk of death compared with non-users [5]. To better understand these contradictions, we analyzed the data of these articles through meta-analysis. Our work shows no significant statistical difference between use and non-use of famotidine reducing the risk of serious disease in COVID-19 patients after Propensity Score Matching. One more thing worth noting is, due to the suddenness of the epidemic, many studies cannot be performed ordinarily. This is susceptible to many complex factors. Therefore, more studies with Propensity Score Matching are needed in the future to further shed light on this problem.

Weizheng Li

Weizhengli_0668@163.com

1 Yunfu People's Hospital, Yunfu, China 
Table 1 Extracting the data of Propensity Score Matching from 4 articles

\begin{tabular}{|c|c|c|c|c|c|c|c|}
\hline \multirow[b]{3}{*}{ Zhou 2020} & \multicolumn{4}{|c|}{ Propensity score matching } & \multirow{3}{*}{$\begin{array}{c}\text { HR } \\
\\
-\end{array}$} & \multirow{3}{*}{$\begin{array}{l}\log (\mathrm{RR}) \\
0.5978\end{array}$} & \multirow{3}{*}{$\begin{array}{l}\text { SE } \\
0.1289\end{array}$} \\
\hline & \multicolumn{2}{|c|}{$\begin{array}{l}\text { Famotidine } \\
\text { use }\end{array}$} & \multicolumn{2}{|c|}{$\begin{array}{l}\text { Non-famoti- } \\
\text { dine use }\end{array}$} & & & \\
\hline & 72 & 519 & 198 & 2595 & & & \\
\hline Freedberg 2020 & - & - & - & - & $0.43,95 \%$ CI $0.21-0.88$, P 0.40 & -0.844 & 0.3657 \\
\hline Mather 2020 & - & - & - & - & $0.386,95 \%$ CI $0.202-0.740$, P 0.004 & -0.9519 & 0.3304 \\
\hline Shoaibi 2021 & - & - & - & - & $1.0395 \%$ CI (0.86-1.24), P 0.74 & 0.0296 & 0.092 \\
\hline
\end{tabular}

\begin{tabular}{|c|c|c|c|c|c|c|c|c|c|}
\hline Studv or Subgroup & log[Risk Ratio] & SE & Weight & $\begin{array}{c}\text { Risk Ratio } \\
\text { V. } \text { Random, } 95 \% \mathrm{Cl}\end{array}$ & & $\begin{array}{r}\text { Risk I } \\
\text { IV. Randol }\end{array}$ & $\begin{array}{l}\text { Ratio } \\
\mathrm{m}, 95 \% \mathrm{Cl}\end{array}$ & & \\
\hline Freedberg 2020 & -0.844 & 0.3657 & $20.4 \%$ & $0.43[0.21,0.88]$ & & $\longrightarrow$ & & & \\
\hline Mather 2020 & -0.9519 & 0.3304 & $21.7 \%$ & $0.39[0.20,0.74]$ & & $\longrightarrow$ & & & \\
\hline Shoaibi 2021 & 0.0296 & 0.092 & $29.3 \%$ & $1.03[0.86,1.23]$ & & & & & \\
\hline Zhou 2020 & 0.5978 & 0.1289 & $28.5 \%$ & $1.82[1.41,2.34]$ & & & $\rightarrow-$ & & \\
\hline Total $(95 \% \mathrm{Cl})$ & & & $100.0 \%$ & $0.82[0.46,1.45]$ & & & & & \\
\hline \multicolumn{5}{|c|}{$\begin{array}{l}\text { Heterogeneity: } \text { Tau }^{2}=0.28 ; \mathrm{Ch}^{2}=32.17, \mathrm{df}=3(\mathrm{P}=0.00001) ; \mathrm{I}^{2}=91 \% \\
\text { Test for overall effect: } Z=0.69(\mathrm{P}=0.49)\end{array}$} & 0.01 & ${ }_{\text {famotidine }}^{0.1}$ & non-famot & $\begin{array}{l}10 \\
\text { tidine }\end{array}$ & $100^{\circ}$ \\
\hline
\end{tabular}

Fig. 1 Forest plot: Famotidine versus non-famotidine after Propensity Score Matching

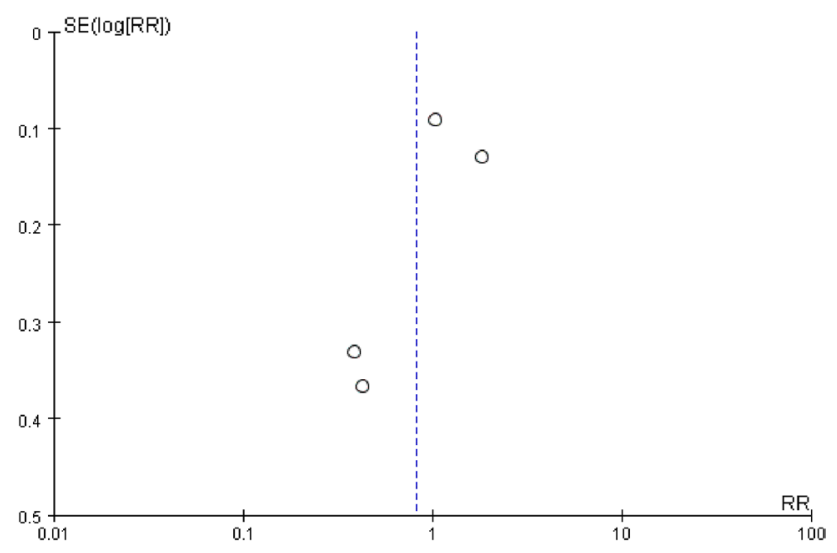

Fig. 2 Funnel plot: Famotidine versus non-famotidine after Propensity Score Matching

\section{Reply}

\section{Further Evidence Suggests No Association Between Famotidine Use and Risk of Severe Disease in COVID-19 Patients}

In this issue of Digestive Diseases and Sciences, Dr. Li and colleagues reported an updated meta-analysis investigating the association between famotidine and risk of serious disease in Coronavirus Disease 2019 (COVID-19) patients in response to our original meta-analysis with same topic of interest [1].
Dr. Li and colleagues included four original studies with effect values after Propensity Score Matching, which also found that famotidine use was not associated with change of the risk of serious disease in COVID-19 patients, similar to our conclusion [1]. Li et al. excluded one study conducted by Freedberg et al [2]. In our meta-analysis, this study was excluded for sensitivity analysis which proved the stability of our results, as excluding this study did not significantly change our result [1]. This updated meta-analysis performed by Dr. Li and colleagues provided further evidence that famotidine use was not associated with either reduced or increased risk of severe disease in COVID-19 patients. However, one limitation that shared both by the meta-analysis conducted Dr. Li and his colleague and our meta-analysis was the small number of included studies due to the limited number of original studies conducted so far. Another unsolved question, as pointed out by Dr. Malone, is whether higher dose of famotidine can provide clinical benefits [6]. However, its efficacy and effectiveness in higher dose when used as a single agent for treatment of COVID-19 can hardly be known, as most studies applied multi-agent strategies when treating COVID-19 patients [6]. Thus, future studies will also need to investigate the effects of different famotidine doses on COVID-19.

In addition to famotidine, proton pump inhibitors (PPIs) are also widely used in clinical practice. Recent meta-analysis found that PPIs might be associated with worse composite poor outcome, as well as an increased risk of severe disease and secondary infection in COVID-19 patients [7, 8]. Considering the current available evidence, it might be more reasonable to choose famotidine over PPIs for COVID-19 
patient when applicable. However, given that both PPIs and Histamine type 2 receptor antagonists such as famotidine are widely used, further studies investigating their effects on COVID-19, especially Randomized controlled trials (RCTs) and other well-designed prospective studies, are urgently needed for the current COVID-19 pandemic.

Chenyu Sun, MD, MSc ${ }^{1, *}$, Yue Chen ${ }^{2}$, Chandur Bhan, $\mathrm{MD}^{1}$, Mubashir Ayaz Ahmed, $\mathrm{MD}^{1}$, Lei $\mathrm{Hu}^{2}$, Yile $\mathrm{Wu}$, $\mathrm{MPH}^{3,4}$, Mingming Liang, $\mathrm{MPH}^{3,4}$, Zhichun Guo ${ }^{5}$, Hongru Yang ${ }^{5}$, Yijing Zuo ${ }^{5}$, Yue Yan $^{5}$, Qin Zhou, $\mathrm{PhD}^{6}$

1. Internal Medicine, AMITA Health Saint Joseph Hospital Chicago, 2900N. Lake Shore Drive, Chicago 60657, Illinois, USA

2. Department of Clinical Medicine, School of the First Clinical Medicine, Anhui Medical University, No. 81 Meishan Road, Hefei 230032, Anhui, P.R. China.

3. Department of Epidemiology and Health Statistics, School of Public Health Anhui Medical University, No. 81 Meishan Road, Hefei 230032, Anhui, P.R. China.

4. Center for Evidence-Based Practice, Anhui Medical University, No. 81 Meishan Road, Hefei 230032, Anhui, China.

5. Massachusetts College of Pharmacy and Health sciences, 179 Longwood Ave, Boston, MA 02115, USA

6. Radiation Oncology, Mayo Clinic, 200 First Street SW, Rochester, MN, 55905, USA

*Correspondence to:

Chenyu Sun, MD, MSc, AMITA Health Saint Joseph Hospital Chicago, 2900 N. Lake Shore Drive, Chicago, 60657, Illinois, USA.

Email: drsunchenyu@yeah.net

Open Access This article is licensed under a Creative Commons Attribution-NonCommercial 4.0 International License, which permits any non-commercial use, sharing, adaptation, distribution and reproduction in any medium or format, as long as you give appropriate credit to the original author(s) and the source, provide a link to the Creative Commons licence, and indicate if changes were made. The images or other third party material in this article are included in the article's Creative Commons licence, unless indicated otherwise in a credit line to the material. If material is not included in the article's Creative Commons licence and your intended use is not permitted by statutory regulation or exceeds the permitted use, you will need to obtain permission directly from the copyright holder. To view a copy of this licence, visit http://creativecommons.org/licenses/by-nc/4.0/.

\section{References}

1. Sun $\mathrm{C}$ et al. Does famotidine reduce the risk of progression to severe disease, death, and intubation for COVID-19 patients? A systemic review and meta-analysis. Dig Dis Sci. 2021. https://doi. org/10.1007/s10620-021-06872-z.

2. Zhou $\mathrm{J}$ et al. Proton pump inhibitor or famotidine use and severe COVID-19 disease: a propensity score-matched territory-wide study. Gut. 2020. https://doi.org/10.1136/gutjnl-2020-323668.

3. Freedberg DE et al. Famotidine use is associated with improved clinical outcomes in hospitalized COVID-19 patients: a propensity score matched retrospective cohort study. Gastroenterology 2020;159:1129-1131.e1123. https://doi.org/10.1053/j.gastro.2020. 05.053 .

4. Mather JF, Seip RL, McKay RG. Impact of famotidine use on clinical outcomes of hospitalized patients with COVID-19. Am. J. Gastroenterol. 2020;115:1617-1623. https://doi.org/10.14309/ ajg.0000000000000832.

5. Shoaibi A, Fortin SP, Weinstein R, Berlin JA, Ryan P. Comparative effectiveness of famotidine in hospitalized COVID-19 patients. Am. J. Gastroenterol. 2021. https://doi.org/10.14309/ajg. 0000000000001153.

6. Malone RW. More than just heartburn: does famotidine effectively treat patients with COVID-19? Digest Dis Sci. 2021. https://doi. org/10.1007/s10620-021-06875-w.

7. Yan C, Chen Y, Sun $C$ et al. Will proton pump inhibitors lead to a higher risk of COVID-19 infection and progression to severe disease? A meta-analysis. Jpn J Infect Dis. 2021. https://doi.org/ 10.7883/yoken.JJID.2021.074.

8. Pranata R, Huang I, Lawrensia S et al. Proton pump inhibitor on susceptibility to COVID-19 and its severity: a systematic review and meta-analysis. Pharmacol Rep. 2021. https://doi.org/10.1007/ s43440-021-00263-x.

Publisher's Note Springer Nature remains neutral with regard to jurisdictional claims in published maps and institutional affiliations. 